\title{
Blade Polymeric Material Study of a Cross-Flow Water Turbine Runner
}

\begin{abstract}
DANIEL CATALIN STROITA, ADRIANA SIDA MANEA*, ANGHEL CERNESCU
Politehnica University of Timisoara, 1 Mihai Viteazu Blvd., 300222, Timisoara, Romania

Although Romania has a consistent hydro energetic potential, till now is valuated just approximate 30 percent of it. On the big rivers there are already installed high power hydro plants, but a lot of small and medium rivers are not valuated energetically. Installing a new high power hydro plant tends to affect the zone, being necessary a lot of changes in the environment. The Cross-Flow hydraulic turbines don't need very complex hydro settlements, being very suitable for small and medium power hydro plants. Also a quite big potential in the use this type of hydraulic machines is the energy recovery in the water treatment and sewage plants. The turbine's blades surfaces enters in contact with the pressurized water jet. The water jet creates a hydrodynamic force that tends to stress the blade. Mainly the Cross-flow turbine blades are made from steel. This article presents the hydrodynamic design and the possibility of using new polymeric material Delrin ${ }^{\circledR A F}$ for the Cross-Flow turbine runner blades, together with the stress analysis.
\end{abstract}

Keywords: polymeric material, blade design, Cross-Flow turbine runner, Von Misses analysis

The Cross-Flow water turbine [1-5] is an action type turbine, having a cylindrical runner mainly, composed from two discs and curved blades flushed in a cylindrical ring. The water enters the runner through a wicket gate, which drives it such as at entrance the attack angle is constant. The water which gets out from the nozzle, passes through the runner blades two times, giving $2 / 3$ of the hydraulic energy at the first passing and $1 / 3$ on the second one. In figure1 is presented a vertical section through a Cross-Flow runner and the water flow path inside it.

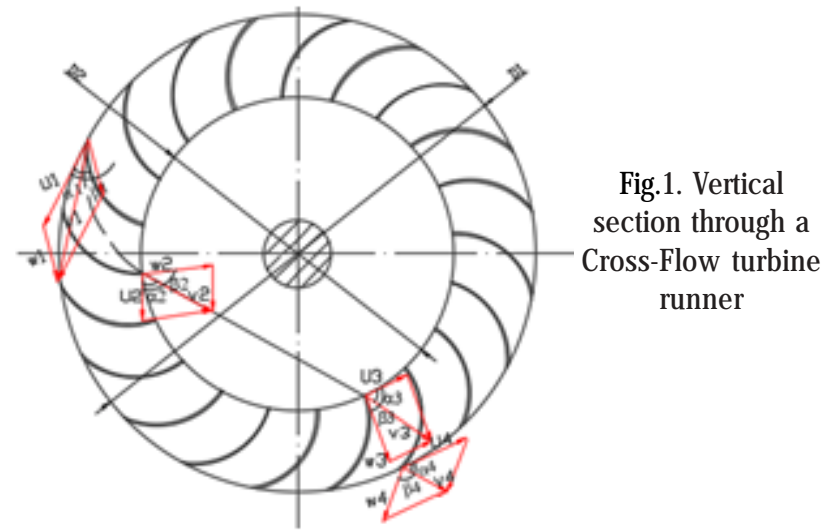

Generally the Cross-Flow turbine blades are circle arcs with constant width. The variable thickness blade has the advantage of a smoothly modification of the inter blade channel. The blade shape was designed using 0. Popa method [6], the geometry being generated using a trigonometrical $6^{\text {th }}$ grade polynomial, (fig. 2). The sharp

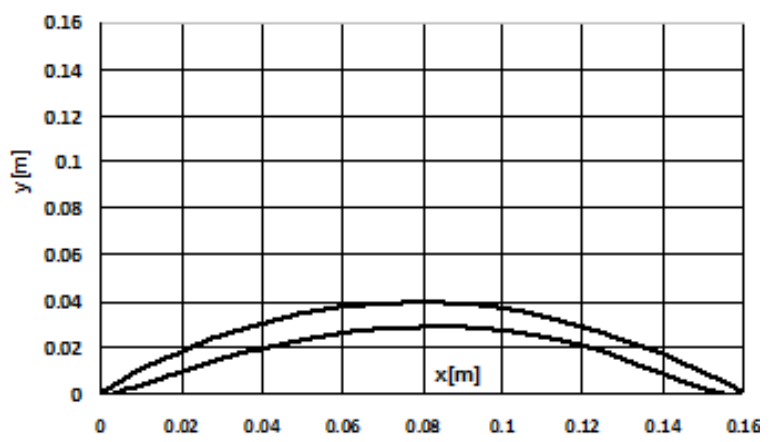

Fig.2. Cross-Flow turbine blade with variable thickness blade edge ensures with minimal losses the stream distribution at runner inlet. Although with classic machining was quite difficult and expensive to make the shape of the blade, the new methods and materials make this possible in quite an easy manor. Usually, the Cross-Flow turbine blades are made from steel. The development of the new polymeric materials, and of the new technologies, make possible the implementation of these two in the CrossFlow runners and blades manufacturing.

This paper presents the hydro-dynamic blade design and a study from strength of materials point of view of some suitable polymeric materials class for the turbine blades.

\section{The Cross-Flow turbine hydrodynamic runner and blade sizing}

The analysed blade is intended to be used for a CrossFlow turbine with a head of $\mathrm{H}=40 \mathrm{~m}$ and a volumetric flow rate of $Q=1.8 \mathrm{~m}^{3} / \mathrm{s}$. The stereo-mechanical power of the turbine is:

$$
P_{s}=\rho g Q H_{T} \eta_{T}
$$

in which it is assumed an efficiency $\eta_{T}=0.8$, water density $\rho=1000 \mathrm{~kg} / \mathrm{m}^{3}$ and gravitational acceleration $g=9.8065$ $\mathrm{m} / \mathrm{s}^{2}$. The speed of rotation of the hydraulic turbine's runner is selected between the synchronization speeds with a.c. frequency $50 \mathrm{~Hz}$ namely:

$$
n=\frac{3000}{p p}[\mathrm{rev} / \mathrm{min}], \quad n_{s}=n \frac{\sqrt{P_{s}[\mathrm{~kW}]}}{H_{T}{ }^{5 / 4}}
$$

in which $\mathrm{pp}=1, \mathrm{~N}$ are the pole pairs of the electric generator. The specific speeds for the Cross-Flow hydraulic turbines are $n_{s}=50 \ldots 150$.

Runner diameter is:

$$
D_{1}=\frac{n_{11} \sqrt{H_{T}}}{n}[\mathrm{~m}], \quad n_{11}=40 \mathrm{rev} / \mathrm{min}
$$

Absolute flow velocity at the entrance in the runner:

$$
v_{1}=k_{\mathrm{v} 1} \sqrt{2 g H_{T}}[\mathrm{~m} / \mathrm{s}]
$$

where $k_{v 1}=0.98$ depends on the nozzle hydrodynamics. Runner tăngential velocity is:

$$
u_{1}=\frac{\pi D_{1} n}{60}[\mathrm{~m} / \mathrm{s}]
$$


Absolute velocity angle is:

$$
\alpha_{1}=a \tan \frac{\sqrt{v_{1}^{2}-4 u_{1}^{2}}}{2 u_{1}}
$$

Runner angles are:

$$
\begin{gathered}
\beta_{4}=a \tan \left(2 \tan \alpha_{1}\right) \\
\beta_{1}=180^{\circ}-\beta_{4}=150^{\circ}, \beta_{4}=30^{\circ} \text { also it is assumed: } \\
\beta_{2}=90^{\circ}=\beta_{3}
\end{gathered}
$$

Inner runner diameter was obtained through an iterative procedure

$$
D_{2}=D_{1} \sqrt{\frac{-\sin ^{2} \beta_{4}+\sqrt{\sin ^{4} \beta_{4}+4 \frac{\sin ^{2} \beta_{1}}{\sin ^{2} \beta_{2}} \cos ^{2} \beta_{4}}}{2 \cos ^{2} \beta_{4}}}
$$

The relative velocities are:

$$
w_{1}=-\frac{v_{1} \cos \alpha_{1}}{2 \cos \beta_{1}} \quad w_{2}=w_{1} \frac{D_{1}}{D_{2}} \frac{\sin \beta_{1}}{\sin \beta_{2}}
$$

The literature gives different formulas for the turbine hydraulic efficiency. So it is accepted:

$$
\eta_{h T}=0.887-\frac{D_{1}}{H_{T}} 0.717
$$

So we consider acceptable the estimated overall efficiency of the cross-flow hydraulic turbine $\eta T=0.8$. The blades number after an empirical formula: $z=4 \times$ INT ( 10 . $\left.D_{1}-1\right)=24$. The transport velocity by the inner diameter of the runner:

$$
u_{2}=u_{1} \frac{D_{2}}{D_{1}}[\mathrm{~m} / \mathrm{s}]
$$

The flow angle here is:

$$
\begin{gathered}
\alpha_{2}=a \tan \frac{w_{2} \sin \beta_{2}}{u_{2}-w_{2} \cos \beta_{2}}[\mathrm{rad}] \quad \varepsilon=2 \alpha_{2} \\
v_{2}=\frac{u_{2}-w_{2} \cos \beta_{2}}{\cos \alpha_{2}}[\mathrm{~m} / \mathrm{s}]
\end{gathered}
$$

Runner width

$$
b_{r}=\frac{Q}{k \cdot k_{v 1} \cdot D_{1} \sqrt{2 g H_{T}}}+0.02[\mathrm{~m}], \quad k=0.1 \text { ( }
$$

The Cross-Flow turbine runner has the main geometric sizes $D_{1}=0.76 \mathrm{~m}, D_{2}=0.44 \mathrm{~m}$ and the width $L=0.884 \mathrm{~m}$. The turbine blade geometry has been generated transposing the circles network in an airfoils netw ork, (fig. 3).

The network characteristics results from the singularization of the network, obtaining the coefficients of approximation trigonometric polynomial. The blade geometry was approximated through a 6 order trigonometric polynomial. The blade coordinates are:

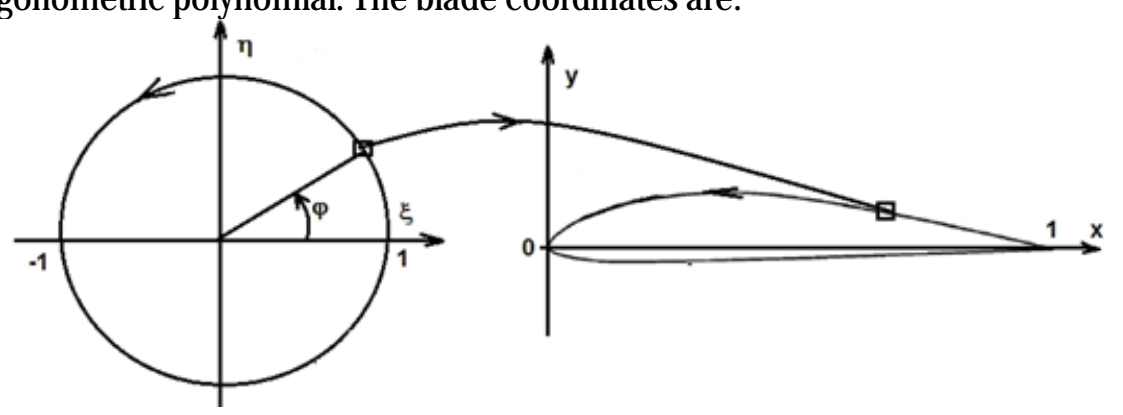

$$
\begin{aligned}
& X=\frac{1}{2}(1+\cos \varphi), \quad Y=\frac{a_{0}}{2}+\sum_{n=1}^{N}\left[a_{n} \cos (n \varphi)+b_{n} \sin (n \varphi)\right](16) \\
& Y=Y(\varphi), \varphi \hat{\imath}[0,2 p], . \text { For } \mathrm{N}=6 \text { coefficients, is considered }
\end{aligned}
$$
$\Delta \varphi=\frac{\pi}{6}$. In order to obtain the trigonometrical polynomial coefficients are considered 12 values for $Y_{p}, p=0,1,2 \ldots$ $(2 \mathrm{~N}-1)$. With these values are calculated the coefficients of the trigonometrical polynomial:

$$
a_{n-\frac{1}{N}} \sum_{p=0}^{2 N-1} Y_{p} \cos \left(p \frac{n \pi}{N}\right), \quad b_{n} \frac{1}{N} \sum_{p=0}^{2 N-1} Y_{p} \sin \left(p \frac{n \pi}{N}\right)
$$

For the studied blade, the trigonometrical polynomial coefficients are presented in table 1.

\section{Force on blade calculation}

In this case we analyzed the hardest condition, this was when the runner is completely blocked and on it acts the whole force of the water jet.

As it is known from the fluid mechanics theory the force of the jet is:

$$
F_{j}=\rho Q \Delta v
$$

where: $\rho=1000\left[\mathrm{~kg} / \mathrm{m}^{3}\right]$ is the water density, $Q=1.8\left[\mathrm{~m}^{3} /\right.$ $\mathrm{s}]$ is the volumetric flow rate, $\Delta v=28[\mathrm{~m} / \mathrm{s}$ ] is the absolute velocity variation (we considered the mosthard condition, when the velocity variation is equal with the velocity from the pipe). As we know from the geometry the jet attacks three blade channels, it means that for one blade force calculation we must consider the formula:

$$
F_{j b}=\rho \frac{Q}{3} \Delta v
$$

After calculus results that $F_{j b}=16800 \mathrm{~N}$.

\section{Material study}

In many mechanical solutions, the thermoplastic resins are a very good alternative solution for the conventional materials [7-12]. From this material class, the acetal homo polymer presenta combination of physical and mechanical properties which permits them to compete easy with metals. The acetals are formed from a group of aldehyde or ketone which reacts nucleophile with alcohol in the presence of an acid catalyst [13]. The acetal ensures a high resistance and rigidity associated with a good dimensional stability and machinability. Also it is characterized through a low friction coefficient and good wear properties, especially in wet medium. The acetal absorbs minimal humidity quantities, keeping it's properties constants in a big variety of media. The low water absorption confers an excellent dimensional stability for the parts machined with high precision. From acetals homo polymers Delrin $® A F$ gain a large scale recognition because of it's reliability and performance in many domains of

\begin{tabular}{|c|c|c|c|c|c|c|c|}
\hline $\mathrm{n}$ & 0 & 1 & 2 & 3 & 4 & 5 & 6 \\
\hline $\mathrm{a}_{\mathrm{n}}$ & 0.205 & -0.002476 & -0.108 & 0.0003333 & 0.0045 & 0.002143 & 0.001 \\
\hline $\mathrm{b}_{\mathrm{n}}$ & 0 & 0.036 & -0.002309 & 0.003667 & 0.002887 & 0.001224 & 0 \\
\hline
\end{tabular}

Fig. 3. Conformal mapping of the unit circle external domain into the external domain of an airfoil 
mechanical engineering [14]. From producer datasheet Delrin ${ }^{\circledR} A F$ presents the following mechanical properties given in table 2.

Table 2

DELRIN ®AF MATERIAL MECHANICAL PROPERTIES [8]

\begin{tabular}{|c|c|c|c|}
\hline Material & $\begin{array}{c}\text { Modulus of } \\
\text { elasticity, } \\
\mathrm{E}[\mathrm{MPa}]\end{array}$ & $\begin{array}{c}\text { Tensile } \\
\text { strength } \\
\sigma_{\mathrm{r}}[\mathrm{MPa}]\end{array}$ & $\begin{array}{c}\text { Elongation } \\
\text { at break } \\
\text { A [\%] }\end{array}$ \\
\hline Delrin $8 \mathrm{AF}$ & 3200 & 70 & 15 \\
\hline
\end{tabular}

\section{The finite element simulation}

Taking into account the blade geometry and the load resulted from hydro dynamic calculus, (fig. 4), it has been made a numerical analysis of the blade stress and strain. The material is defined elastic linear with properties similar with the acetal Delrin ${ }^{\circledR} A F$. The blade support conditions have been established according to it's mounting solution in the runner, considering also two intermediary supports, (fig. 5).
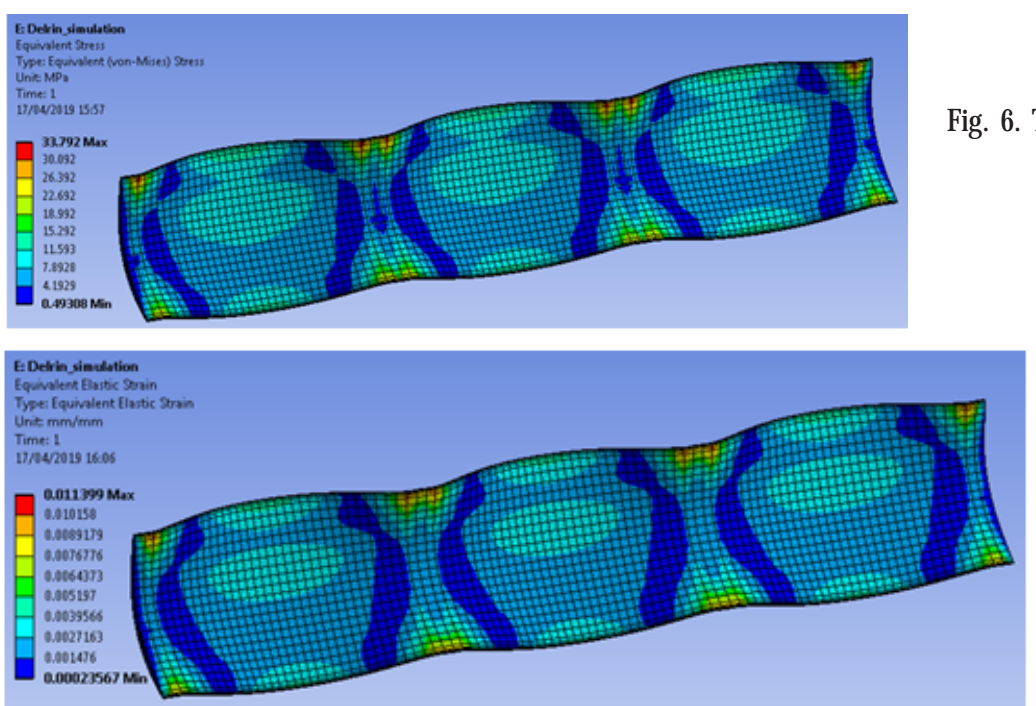

Fig. 7. The equivalent Von Mises strain field

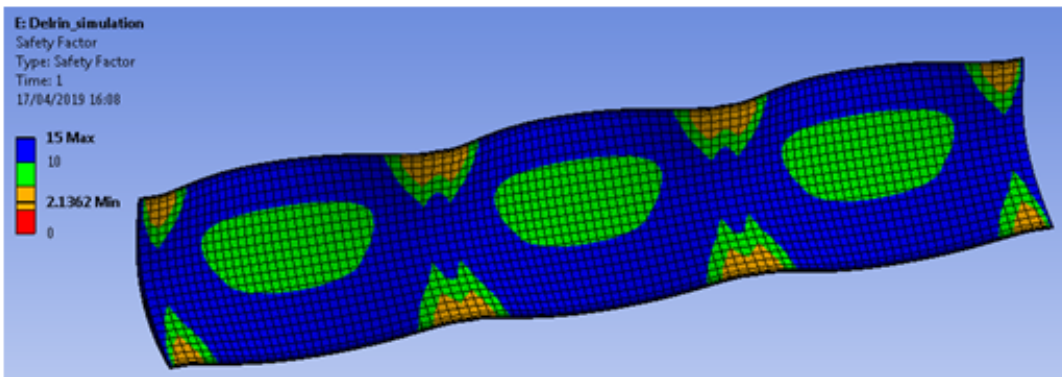

Fig. 8. The safety factor distribution

The figure 6 and 7 presents the Von-Mises equivalent stress and strain distributions for the considered loading case. As a result of blade geometry and deformation modulus can be seen stress concentrations in the blade upper part, nearby the supports. However these stress concentrations give a relatively good safety coefficient accepted in the design standards of these components, (fig. 8).

The use of thermoplastic materials in Cross-Flow hydraulic turbines blades and runners has many advantages as: good mechanical resistance, easy machining because of lower density than metals, the hydraulic machine components having a reduced weight. For the studied case the blade volume is de 0.00127652 $\mathrm{m}^{3}$. In the case in which the blade will be machined from steel, for a medium steel density of $7850 \mathrm{~kg} / \mathrm{m}^{3}$, will give a blade mass of $10 \mathrm{~kg}$. If Delrin material is used, having the density of $1420 \mathrm{~kg} / \mathrm{m}^{3}$, the blade will have the mass of $1.812 \mathrm{~kg}$, being almost 5.5 times lighter.

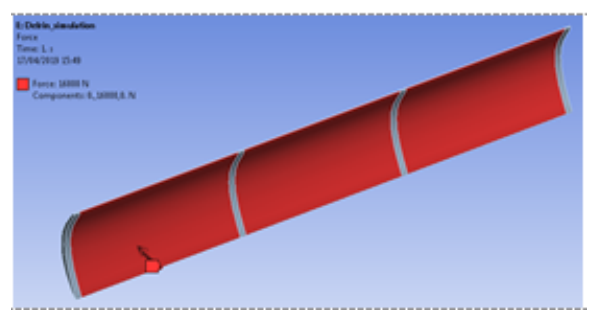

Fig. 4. The hydro dynamic force applied on blade inner surface

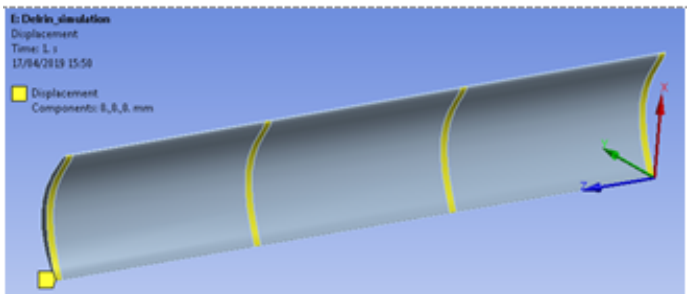

Fig. 5. Supports applied on both blade surfaces

Fig. 6. The equivalent Von Mises stress distribution

\section{Conclusions}

The Cross-Flow turbines with polymeric material runners, can be used as energy recovering units in water treatment plants and also in sewage plants, being suitable for relatively small heads and variable flows.

The analytical knowledge of the geometry is useful for the future analysis of the blade behavior. The 0. Popa method permits the establishment of any blade design using trigonometrical polynomials.

In order to analyze the blade it is necessary to size the turbine runner, knowing mainly the geometric parameters, the sizing method is given in the presented paper.

The use of new materials in the accomplishment of Cross-Flow hydraulic turbines components, permits the utilization of these machines for energy production also with dirty waters.

From variable thickness blade analysis designed for a Cross-Flow turbine, is concluded that the thermoplastic 
material Delrin, presents advantages which recommends it to be used for this turbine type runners.

\section{References}

1.YOUNG-DO, C; JAE-IK, L., YOU-TAEK, K., YOUNG-HO, L., Effect of Blade Angle on the Performance of a Cross-Flow Hydro Turbine, J ournal of the Korean Society of Marine Engineering, 32. 10.5916/ jkosme.2008.32.3.413, 2008.

2.STROITA, D.C., Identificarea dinamica a turbinelor cu dublu flux, teza de doctorat, Ed. Politehnica, Timisoara 2009.

3.TREINEN, S., Conception dimensionnement et fabrication d'une turbine Banki de type JLA mecano-soudee, Ed. Gramme, Paris, 2005. 4.STROITA, D.C., BARGLAZAN, M; MANEA, A.S.;BALASOIU, V., Doubleflux water turbine dynamics, Proceedings of the $19^{\text {th }}$ International DAAAM Symposium Intelligent Manufacturing $\&$ Automation: Focus on New Generation of Intelligent Systems and Solutions $22-25^{\text {th }}$ October 2008, pp. 1325-1326.

5.MANEA, A.S., Complemente de hidrodinamica turbomasinilor, Ed. Mirton, Timisoara, 2006

6.MANEA, A.S., STROITA, D.C., Efficient Hydro Energy Using In Romania, Energetika, Ekologija, Ekonomija, No 2/year XII, UDC 620.9, Zlatibor, 2010, pp. 087-090.

7.MITELEA, I., VARZARU, N., BORDEASU, I., POPESCU, M., The High Frequency Welding Aptitude of Thermoplastic Polymers, Mat. Plast. 46, no. 1, 2009, p.101-107
8.CAPLESCU, C., MARSAVINA, L., BORDEASU, I., SECHEI, R., M., The Fracture of Polyurethane Materials in the Presence of Stress Concentrators, Mat. Plast. 47, no. 3, 2010, p.379-382

9.TEODOR, M., BORDEASU, I., BADARAU, R., BE) , A., BORDEASU, D., Failure Cause Analysis of a $5 \mathrm{KW}$ Wind Turbine Blade in Extreme Wind Conditions, Mat. Plast, 50, no. 4, 2013, p.279-284

10.MICU, L.M, LAZAR, I., CIRCIUMARU, A.,BORDEASU, I., PIRVULESCU,L.D., HLUSCU, L.M., New Results Regarding Cavitation Behavior of Polymers Modified with Anorganic Substances Coated on BronzeSurfaces Mat. Plast., 55, no. 3, 2018, p. 460-463

11.BORDEASU,I., CIRCIUMARU,A., POPOVICIU, M O., LAZAR, I., BADARAU, R., GROZA, I., Cavitation Erosion Behavior on Thin Films of Polymer BlendsDeposited Over Bronze Surfaces, Mat. Plast, 55, no. 3, 2013, p.286-290,

12.LAZAR, I., BORDEASU, I., CIRCIUMARU, A., MITELEA, I., BOCII, L. S., Behavior of Polymer Thin Films Deposed on Bronze Surfacesat Cavitation Erosion, Rev. Chim. (Bucharest), 69, no. 10, 2018, p.29212927

13.*** http://www.chem.ucalgary.ca/courses/350/Carey5th/Ch17/ch173-4-2.html;

14.*** Delrin - acetal resin, Design Information, DuPont, http:// www2.dupont.com/Plastics/en_US/assets/downloads/design/ DELDGe.pdf

Manuscript received: 17.02 .2019 